Provided for non-commercial research and education use. Not for reproduction, distribution or commercial use.

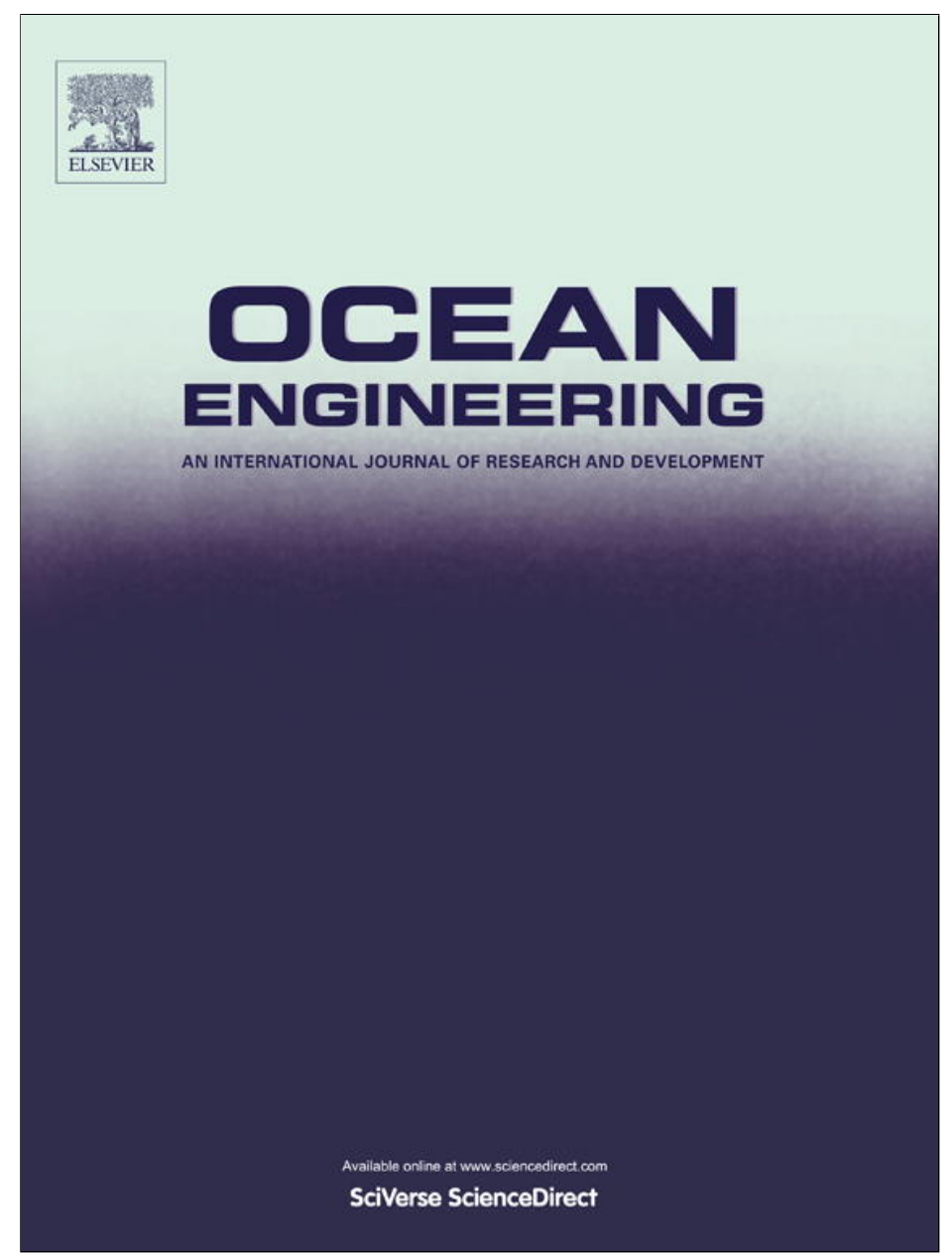

(This is a sample cover image for this issue. The actual cover is not yet available at this time.)

This article appeared in a journal published by Elsevier. The attached copy is furnished to the author for internal non-commercial research and education use, including for instruction at the authors institution and sharing with colleagues.

Other uses, including reproduction and distribution, or selling or licensing copies, or posting to personal, institutional or third party websites are prohibited.

In most cases authors are permitted to post their version of the article (e.g. in Word or Tex form) to their personal website or institutional repository. Authors requiring further information regarding Elsevier's archiving and manuscript policies are encouraged to visit:

http://www.elsevier.com/copyright 


\title{
Directional spreading model in a wave channel: Wave propagation and wave breaking
}

\author{
D.R.C.B. Neves ${ }^{\text {a,* }}$, L.A.M. Endres ${ }^{\text {b }}$, C.J.E.M. Fortes ${ }^{c}$, T. Okamoto $^{\mathrm{d}}$ \\ a National Laboratory of Civil Engineering, Av. do Brasil 101, 1700-066 Lisbon, Portugal \\ ${ }^{\mathrm{b}}$ Federal University of Rio Grande do Sul, Av. Bento Gonçalves 9500, Porto Alegre 91501-970, Brazil \\ ${ }^{\mathrm{c}}$ National Laboratory of Civil Engineering, Av. do Brasil 101, Lisbon 1700-066, Portugal \\ ${ }^{\mathrm{d}}$ University of Hiroshima, 1-5-1 Kagamiyama, Higashi-Hiroshima, Hiroshima 739-8529, Japan
}

\section{A R T I C L E I N F O}

\section{Article history:}

Received 13 December 2011

Accepted 1 July 2012

\section{Keywords:}

Wave breaking

Directional spreading model

Physical modelling

Wave channel

\begin{abstract}
A B S T R A C T
The presented work describes a wide range of wave channel tests performed at the National Laboratory of Civil Engineering (LNEC) with the main objective of introducing an extensive wave analysis regarding mainly the directional spreading analysis of the wave propagation under conditions of wave breaking on complex bathymetries. Therefore, this paper shows the experimental setup, the incident wave conditions, the measurements (free surface elevation and particle velocity) along the wave channel, especially at the wave breaking zone. Based upon the time series of the wave data measurements, a time, spectral and statistical analysis was performed and presented. Analyses are presented relating to: (i) the relative wave height $(H / d)$; (ii) the wave celerity; (iii) the two-dimensional distribution of the particle velocities components; finally (iv) the average wave direction and spreading angle were carried out. The directional spreading analysis was supported by all the other calculated quantities in order to have an effective analysis on the wave breaking phenomena. The work performed contributed for a better understanding of the wave breaking process and especially at the end part of it. Moreover, the data obtained and the results of the performed analysis constitute an important basis for the establishment/improvement of numerical wave breaking models and its validation.
\end{abstract}

(c) 2012 Elsevier Ltd. All rights reserved.

\section{Introduction}

The determination of the wave breaking zone is an important topic for studies referring coastal hydrodynamics and sediment transport issues. More accurately, the location and extension of the wave breaking section are two of the main factors for the coastal structures location and stability of the consequent sediment dynamics.

The physical processes of the wave breaking phenomena are quite different from the normal wave potential flux. In fact, the bottom slopes induce a nearshore wave breaking that persists till the coastline where the complete dissipation of the wave energy occurs. Many studies aimed to analyze the initial process of the wave breaking (Goda, 1970; Weggel, 1972; Tsai et al., 2004; Camenen and Larson, 2007) but the processes after the initial point until the end of the wave breaking are still object of a broad discussion in the scientific community (Svendsen et al., 1978; Tsai

\footnotetext{
* Corresponding author. Tel.: +35121 8443904; fax: +351218443011

E-mail addresses: dneves@lnec.pt (D.R.C.B. Neves), endres@ufrgs.br (L.A.M. Endres), jfortes@lnec.pt (C.J.E.M. Fortes), tokamoto@hiroshima-u.ac.jp (T. Okamoto).
}

et al., 2004). Therefore new scientific approaches are necessary to fill the above mentioned gap.

The traditional wave breaking indexes are usually related with the initial point of the wave breaking, leaving in background the end section of the process, which is, as mentioned above, especially important in coastal dynamics studies and for the set up of maritime structures. In addition, studies on wave breaking considering complex bathymetries (similar to real ones) and different incident wave conditions (according with real sea wave states) are always needed (Okamoto et al., 2010), since a great number of those studies is restricted to simplified bottom schemes and/or to a few incident wave conditions.

Except in a few practical exceptions, accordingly to Lesieur (1997), the so-called "turbulent flow" has to be strongly tri-dimensional and to be able to mix transported quantities much more rapidly than if assuming, for example, the molecular diffusion processes were the only ones involved. In other words, the Reynolds stresses due to the tri-dimensional velocity fluctuations must be present.

Physical modeling can give an important contribution to this topic since under controlled conditions one can analyze minutely the wave transformation during the wave breaking phenomena. Moreover, it is a basis for numerical wave modelling. The numerical 
parameterization and validation of the numerical wave propagation models is usually based on an extensive collection of wave experimental data. Such data allows the establishment/improvement of the existing numerical wave breaking models and the assessment of the numerical wave modelling performance. In this area also becomes necessary the improvement of parameters for a most refined delimitation of the wave breaking section in the numerical wave propagation models.

Following this reasoning, an extensive set of experimental tests on wave propagation over different slope bottoms and considering different incident wave conditions, was carried out to study the wave breaking characteristics and hydrodynamics. Special attention was given to data from the wave breaking section and especially at the end of it.

The experimental tests were performed in a wave channel at the National Laboratory of Civil Engineering (LNEC), in Lisbon, Portugal. For each tested incident wave condition, free surface elevations and particle velocities were measured along the channel. Based on that, several types of wave data analysis were performed for a better understanding of the wave breaking process. The present work was carried out under the Project BRISA (Breaking Waves and Induced Sand Transport), funded by the Foundation for Science and Technology of Portugal. The project's main objective was to give a contribution on the wave breaking phenomena understanding in order to study such influence in the sediment transport for coastal areas. Therefore, the project involves several methodologies (Fortes et al., 2011)_physical modelling, numerical modelling and wave field measurements. The present work fills into the physical modelling methodologies, which objectives were to contribute for a better knowledge of the wave breaking phenomena, the establishment of a new wave breaking model and to collect an important set of data for the numerical modelling validation.

The final goal of the presented work was to develop a numerical model that enabled the definition of the wave breaking section since its beginning till the very ending. Thus, the directional spread calculation proved to be a sensible parameter for the wave breaking phenomena on a wave channel, since it depicts clearly the generated turbulence of the surf zone.

This paper presents the experimental conditions, with the channel description, the incident wave conditions and the experimental procedures (Section 2). Data and results from time, spectral and statistical analysis are presented (Section 3). Moreover, a more in-depth data analysis was carried out for the calculation of several parameters, such as: (i) the definition of the wave breaking zone; (ii) the relative wave height $(H / d)$; (iii) the wave celerity; (iv) the two-dimensional distributions of the velocity components in the $x y, x z$ and $y z$ planes; ( $v$ ) and finally, the most important, the directional analysis with the evaluation of the spreading angle. The paper ends (Section 4) with some final comments.

\section{Experimental settings}

The wave tank experiments were conducted in a wave channel with $32.4 \mathrm{~m}$ length and $0.6 \mathrm{~m}$ width. A beach profile, with different bottom slopes, was constructed as shown in Fig. 1. The slope angle of the front face of the bar and the beach section was fixed with $1: 20$ and the slope of the lee side of the bar was of $1: 80$. Water depth was measured to be $0.1 \mathrm{~m}$ at the crest of the 1:20 bar.

Fig. 1 presents a plan of the wave channel and its background profile from the position of the wave maker.

Along the wave channel, several equipments were installed: the measurement equipments (wave resistive gauges and an Acoustic Doppler Velocimeter (ADV)) to measure free surface elevations and particle velocities; the National Instruments acquisition system to forward the wave generation signal to the wave maker ("piston" type); and a computer named CPU2 to connect and customize the ADV sensor.

At the monitoring office, Fig. 2, the computer named CPU1 was installed to generate the incident wave signal and to acquire and record the data from both the wave resistive gauges and the ADV sensor. The CPU1 computer received the sensor signals through intermediate devices, like the Wave Probe Monitor and the National Instruments acquisition system.

The connection between the computer CPU1 and the wave maker was made through the Signal Express software generating the signal to be sent to the wave maker by the National Instruments acquisition system.

For the data acquisition, the sensors signals elapsed through the Wave Probe Monitor in order to convert the analogical signal in a digital format. Therefore the signal was recorded at the CPU1 computer.

\subsection{Incident wave characteristics and experimental tests}

A piston-type wave maker generated a combination of regular waves combining four wave periods ( $T=1.1,1.5,2.0$ and $2.5 \mathrm{~s}$ ) with four wave heights $(H=12 \mathrm{~cm}, 14 \mathrm{~cm}, 16 \mathrm{~cm}$, and $18 \mathrm{~cm})$. The wave $T=1.1 \mathrm{~s}$ and $H=18 \mathrm{~cm}$ presented a very steep wave that broke in front of the wave maker, therefore, this incident wave condition was excluded from the experimental tests. Thus, in total, for each position along the canal, fifteen combinations of waves were tested (Table 1).

In order to avoid reflection and to absorb the energy at the end of the channel, a very effective horsehair sheet was installed at the shore. A reflection analysis of the given tank was made as a

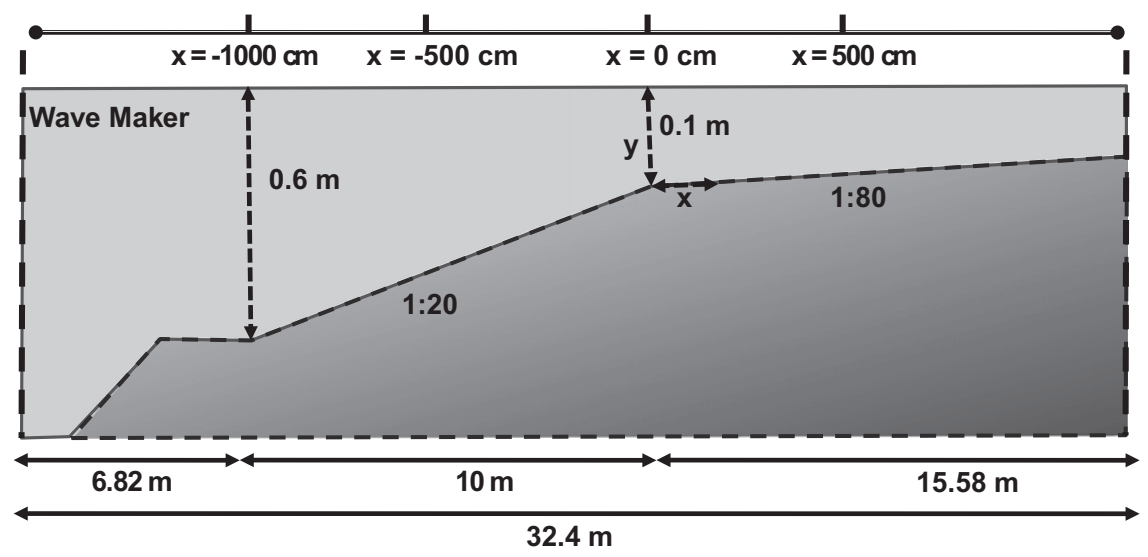

Fig. 1. Wave channel profile and positions along the longitudinal ( $x$ ) axis. 


\section{Experimental Setup}

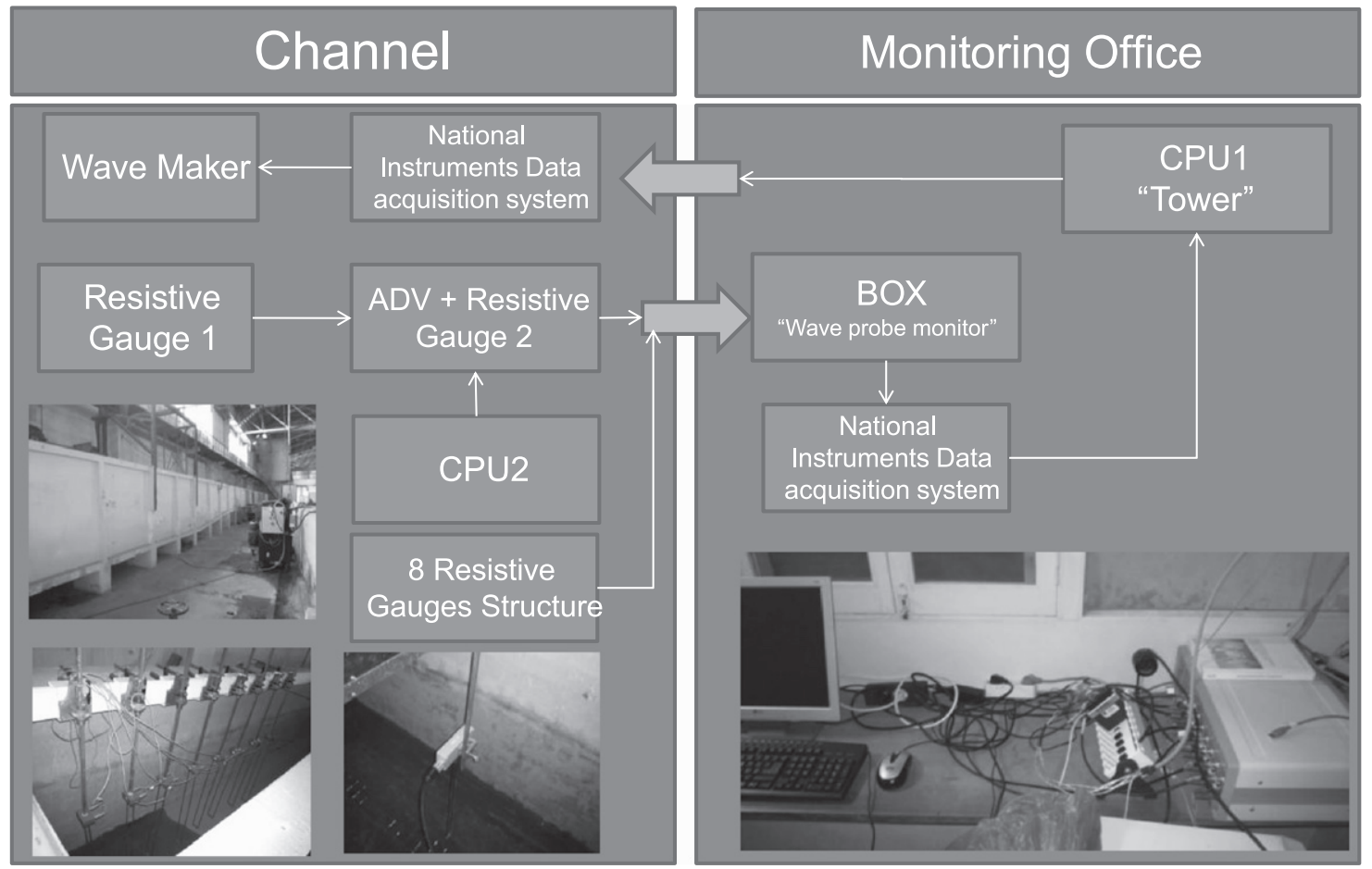

Fig. 2. Experimental setup.

Table 1

Incident wave conditions.

\begin{tabular}{lllll}
\hline$T(\mathrm{~s}) H(\mathrm{~cm})$ & \multicolumn{2}{l}{ Incident wave conditions } \\
\cline { 2 - 5 } & 1.1 & 1.5 & 2.0 & 2.5 \\
\hline 12 & $\mathrm{x}$ & $\mathrm{x}$ & $\mathrm{x}$ & $\mathrm{x}$ \\
14 & $\mathrm{x}$ & $\mathrm{x}$ & $\mathrm{x}$ & $\mathrm{x}$ \\
16 & $\mathrm{x}$ & $\mathrm{x}$ & $\mathrm{x}$ & $\mathrm{x}$ \\
18 & & $\mathrm{x}$ & $\mathrm{x}$ & $\mathrm{x}$ \\
\hline
\end{tabular}

preparatory work for Okamoto et al. (2008). The 15 input wave conditions were tested $(T=1.1-2.5 \mathrm{~s}, H=8-20 \mathrm{~cm})$, it was found that the maximum reflected wave height was $1.3 \mathrm{~cm}$ for $T=2.5 \mathrm{~s}$ and $H=15 \mathrm{~cm}$ and, for most of the cases, the reflected wave height was less than $1 \mathrm{~cm}$. This means that the reflected wave energy was less than $1 \%$ of the input wave energy in most of the cases (the maximum of $2.3 \%$ for $T=2.5 \mathrm{~s}$ and $H=8 \mathrm{~cm}$ ). Therefore, it was concluded that there is no significant reflection back from the shore.

The total set of experiments was divided in two phases: (i) Phase I-the objective of the first phase was to measure free surface elevations along the channel with an 8 wave gauges mobile structure; (ii) Phase II-the objective of the second phase was to measure the particle velocity along the channel in the middle of the water column, using the ADV sensor. At the same time, a resistive gauge was located near the ADV sensor to measure the free surface elevation.

\subsection{Equipment and experimental procedures}

In Phase I, a mobile structure with eight wave gauges was placed along the channel to measure the free surface elevations (Fig. 3). The mobile structure provided an easy transport and allocation of the wave gauges along the channel. The covered length of the wave channel was from the beginning of the first ramp $(x=-1000 \mathrm{~cm})$ till $x=560 \mathrm{~cm}$ when the wave breaking is shown to be completely over for every incident wave condition. To calibrate the input wave height, and since the bottom configuration was not flat, a wave gauge was installed at the toe of the front face of the first slope $(x=1080 \mathrm{~cm})$. Each gauge in the mobile structure was separated by a fixed distance $(20 \mathrm{~cm})$ and measurements separated by $10 \mathrm{~cm}$ were taken along the covered area. The sampling frequency was of $25 \mathrm{~Hz}$.

Important is to note that some positions (only two) are repeated due to limitations of the channel, which contain a set of transverse metal bars that sometimes prevent the placement of the eight gauges structure.

At Phase II, the particle velocity was measured by an Acoustic Doppler Velocimeter (ADV) with a down-looking probe, enabling the three orthogonal components of the suspended particle velocities (volume measurements), Fig. 4. The ADV probe was placed in the middle of the water column. Together with the ADV, in the same transverse section of the channel, a resistive gauge was placed for simultaneous measurements of the free surface elevation, Fig. 4. The sampling rate of both equipment was of $25 \mathrm{~Hz}$.

The ADV positions along the channel were identical to the resistive wave gauges, between $x=-200 \mathrm{~cm}$ and $x=560 \mathrm{~cm}$, with a spacing of $10 \mathrm{~cm}$, and a spacing of $100 \mathrm{~cm}$ between $x=-1000 \mathrm{~cm}$ and $x=-200 \mathrm{~cm}$.

The wave breaking section (from the beginning till the end of the wave breaking zone) was defined by visual observation. The beginning and the end of the wave breaking zone was considered when the air bubbles started tipping over the crest and vanished from the water, respectively. Considering the nature of these observations, about 50 samples were collected and an average value was determined.

Each experimental test (incident wave) had the duration of 490 s. In Fig. 5 the experimental procedures are summarized. 


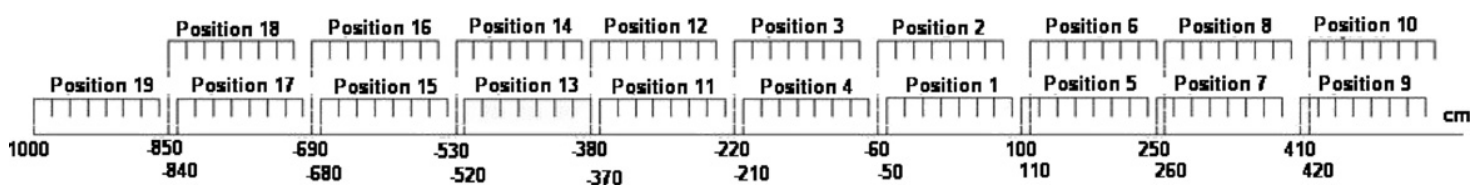

Fig. 3. Wave gauges positions along the channel considering $x=0$ the top of the bar $(\mathrm{cm})$.

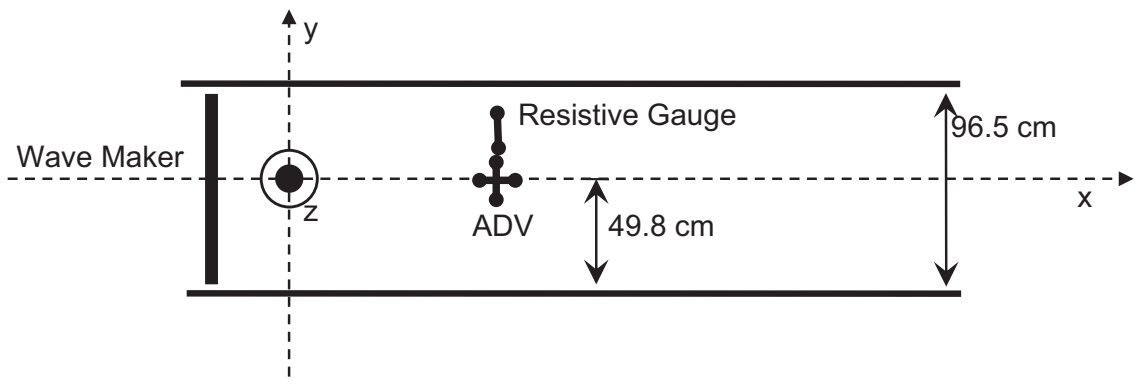

Fig. 4. Plan of the ADV positioning (at the toe of the first slope $(1: 20)$ ).

\section{MEASUREMENTS}

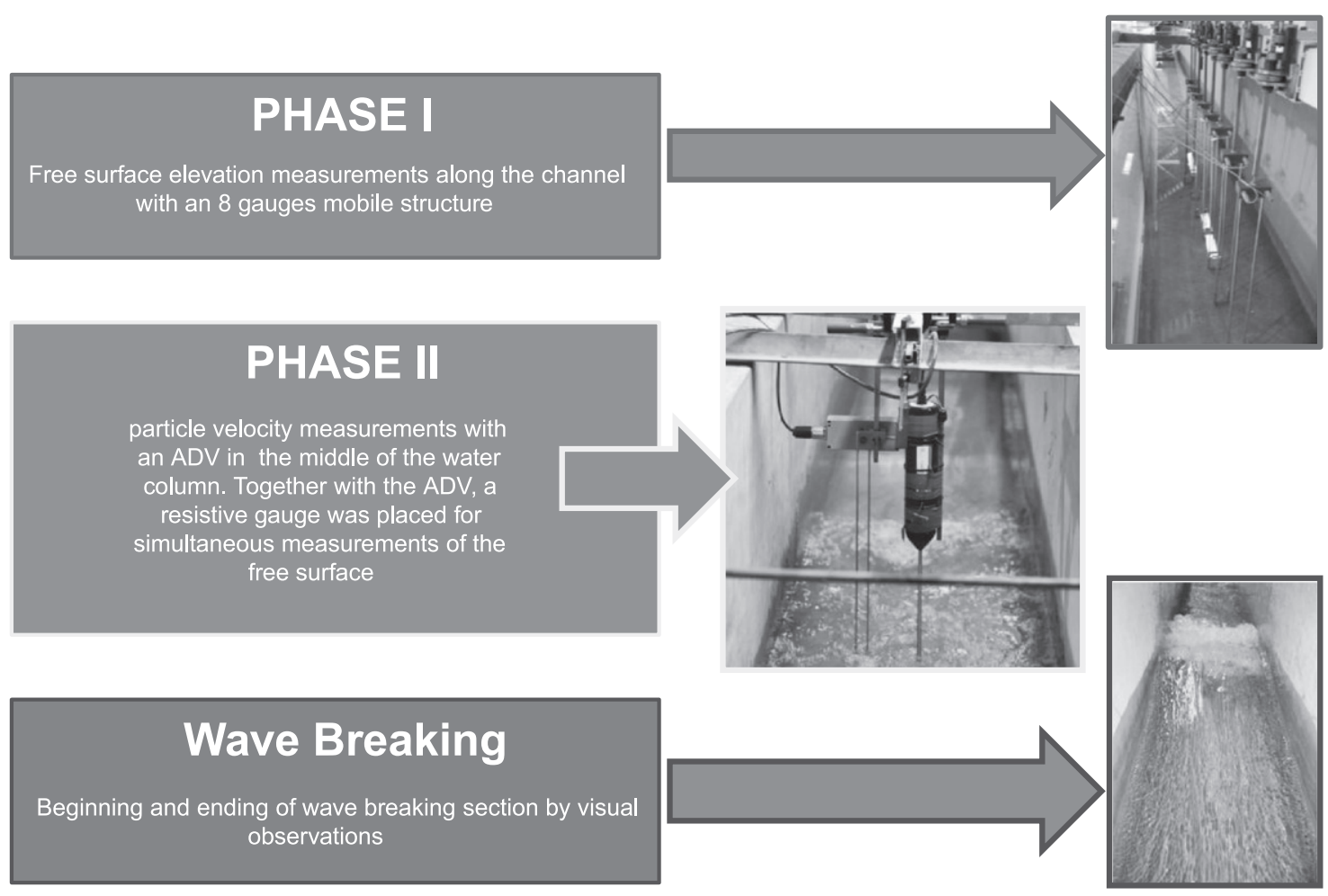

Fig. 5. Experimental tests.

\section{Results}

For each of the 15 incident wave conditions, time series of the free surface elevation and the particle velocity at the middle of the column depth along the wave channel (and especially from $x=-1000 \mathrm{~cm}$ to $x=560 \mathrm{~cm}$ ) were obtained. Based on those data, different types of data analysis were considered:

- Phase I-Time, spectral, and statistical analysis of the free surface elevations. Also the wave celerity and the relative wave height $(H / d)$ along the wave channel were calculated for each incident wave condition.

- Phase II-Time, spectral, and statistical analysis of the particle velocity measurements. Moreover, the ADV measurements allowed the calculation of the particle velocities main characteristics, the two-dimensional distributions of velocity components at the $(x y),(x z)$ and $(y z)$ planes and the average wave direction as well as the directional spread. For the wave direction calculations, the free surface elevation measurements were considered.

Meanwhile, in every experimental test from the above referred phases, the wave breaking section was observed.

In the next sections, the experimental location values for the beginning and ending of the wave breaking zone are presented. Then, for each experimental phase, some samples are presented of the obtained data and the performed analysis. The incident wave condition of $T=1.5 \mathrm{~s}$ and $H=18 \mathrm{~cm}$ was chosen as an example of results for the majority of the presented samples. 


\subsection{Wave breaking zone}

As referred in Section 2.2, the wave breaking section was defined for each one of the 15 incident waves. About 50 samples were obtained and an average value was determined for the initial and terminal location of the wave breaking. Both locations were defined by eye observation, the wave breaking section was defined by the air bubbles that start to appear at the water surface (begin of the wave breaking) and when the air bubbles vanished completely from the water surface (end of the wave breaking) (Table 2).

The Table 2 presents the values of the initial and final location of the wave breaking section for all the 15 incident waves in the tests described above.

\subsection{Phase I results}

In this section, examples of free surface elevation data and the performed data analysis are presented. For each incident wave condition, the data analysis consists on:

- The time, spectral, and statistical analysis of the free surface elevations;

- The calculation of the relative wave height $(H / d)$ and the wave celerity.

\subsubsection{Free surface elevation data}

For each incident wave condition, time series of free surface elevation were obtained. Fig. 6 depict the probe data records, at the positions $x=-1080 \mathrm{~cm}$ (Fig. 6(a)) and $x=500 \mathrm{~cm}$ (Fig. 6(b)) for an incident regular wave with $T=1.5 \mathrm{~s}$ and $H=18 \mathrm{~cm}$, during the time interval between $150 \mathrm{~s}$ and $180 \mathrm{~s}$.

From Fig. 6, a clear wave transformation is observed as the wave propagates to areas of lower depths. The deformed of the free surface presents increasingly non-linear characteristics (sharp crests and elongated troughs). There is also the appearance of some harmonics as the wave propagates to shallower zones.

\subsubsection{Temporal, spectral and statistical analysis}

Based on the free surface records along the channel, was performed:

- The calculation of: (i) $H_{M}$ (maximum wave height); (ii) $H_{s}$ (significant wave height); (iii) $H_{\text {med }}$ (average wave height); (iv)
$T_{s}$ (significant wave period); (v) $T_{\text {med }}$ (average wave period), based on the up-crossing method;

- The statistical analysis of the free surface elevation values: (i) average; (ii) standard deviation; (iii) skewness; (iv) and kurtosis, (Sancho et al., 2001);

- Spectral analysis of the free surface elevation values, allowing the analysis of the nonlinear phenomena and the harmonic generation. The spectral density variance was calculated in order to define the energy distribution in the frequency spectrum.

Fig. 7 shows the significant wave heights and the average wave periods along the channel, for an incident wave of $T=1.5 \mathrm{~s}$ and $H=18 \mathrm{~cm}$.

Fig. 7(a) shows an initial decrease of the $H_{s}$ followed by a significant increase throughout the section close to $x=-400 \mathrm{~cm}$ due to the shoaling effect. Some oscillations on the wave height values are also observed. Subsequently the wave breaking effect produces a significant reduction in the wave height preceded by a section with a constant value for the wave heights at the lee side of the channel due to the ending of the wave breaking.

Tests show that the wave period remains approximately constant throughout the channel (Fig. 7(b)) to be disturbed at the end of the wave breaking zone, showing considerable oscillations of the wave period in the channel section above the $x=150 \mathrm{~cm}$ position. In this last section we observe major changes in the wave period probably because of the generation of higher order harmonics and their interaction after the wave breaking (see Fig. 10). However note that the free surface elevation measurements after the wave breaking section are less accurate, since this section is characterized by a strong turbulence and air emulsion. Therefore, this section is characterized by a considerable dispersion of the experimental values.

The performed statistical analysis of the free surface elevation records corresponds to the average, standard deviation, skewness and kurtosis:

Figs. 8 and 9 present the evolution throughout the channel of the above mentioned parameters for an incident regular wave of $T=1.5 \mathrm{~s}$ and $H=18 \mathrm{~cm}$.

Fig. 8(a) presents the average values of the free surface elevation related to the Mean Water Level (MWL). The figure depicts that the average free surface presents a typical set-down and set-up profile (Dean and Walton, 2009). A slight set-down is observed between the $x=-1000 \mathrm{~cm}$ and $x=-400 \mathrm{~cm}$, when the wave breaking begins

Table 2

Initial and final location of the wave breaking section.

\begin{tabular}{|c|c|c|c|c|c|c|c|c|}
\hline \multirow[t]{2}{*}{$T(\mathrm{~s}) H(\mathrm{~cm})$} & \multicolumn{4}{|c|}{ Initial location of the wave breaking } & \multicolumn{4}{|c|}{ Final location of the wave breaking } \\
\hline & 1.1 & 1.5 & 2.0 & 2.5 & 1.1 & 1.5 & 2.0 & 2.5 \\
\hline 12 & -267 & -212 & -203 & -220 & 205 & 265 & 330 & 445 \\
\hline 14 & -332 & -276 & -289 & -270 & 200 & 245 & 330 & 445 \\
\hline 16 & -427 & -340 & -361 & -295 & 200 & 245 & 305 & 428 \\
\hline 18 & & -395 & -410 & -367 & & 245 & 293 & 415 \\
\hline
\end{tabular}
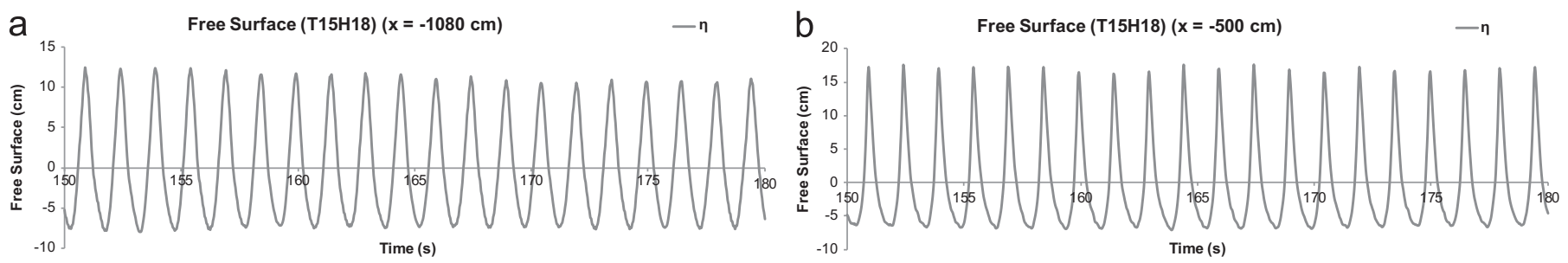

Fig. 6. Free surface elevation (cm), for an incident wave of $T=2.5 \mathrm{~s}$ and $H=18 \mathrm{~cm}$, between the $150 \mathrm{~s}$ and the $180 \mathrm{~s}$ of the wave record at the positions (a) $x=-1080 \mathrm{~cm}$ and (b) $x=-500 \mathrm{~cm}$ 


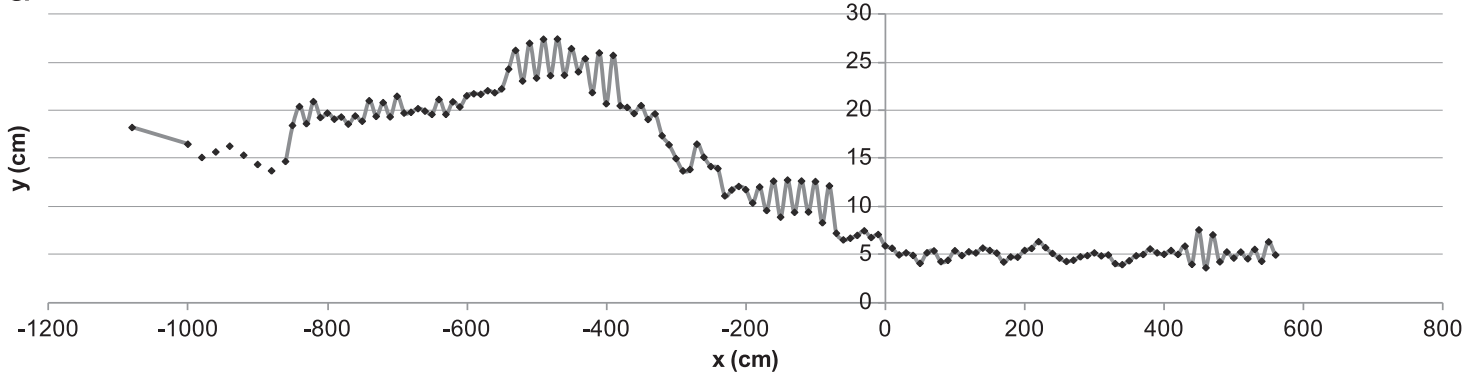

b

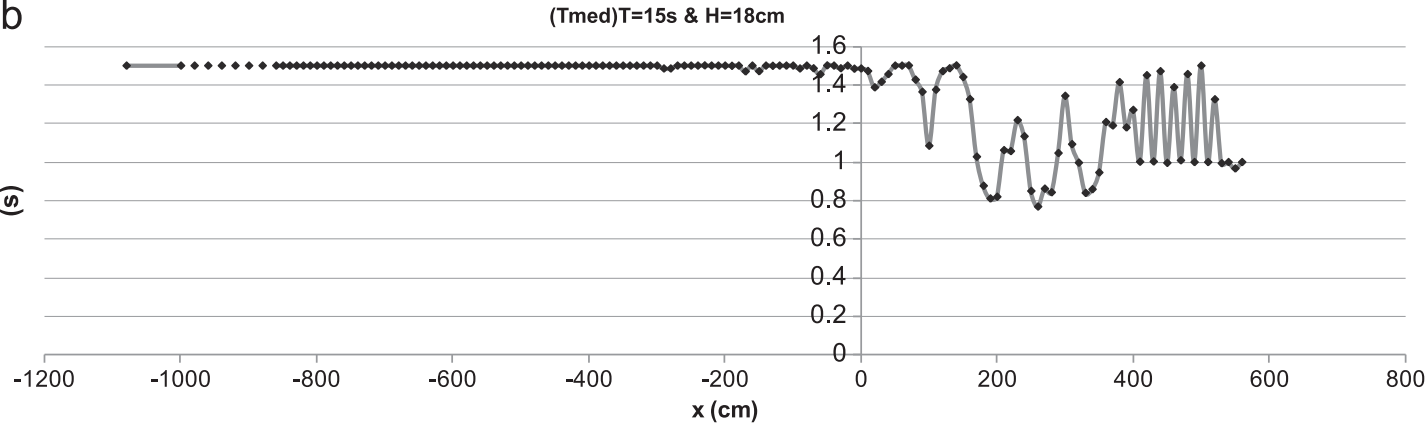

Fig. 7. (a) Significant wave heights and (b) average wave periods for an incident regular wave of $T=1.5 \mathrm{~s}$ and $H=18 \mathrm{~cm}$.
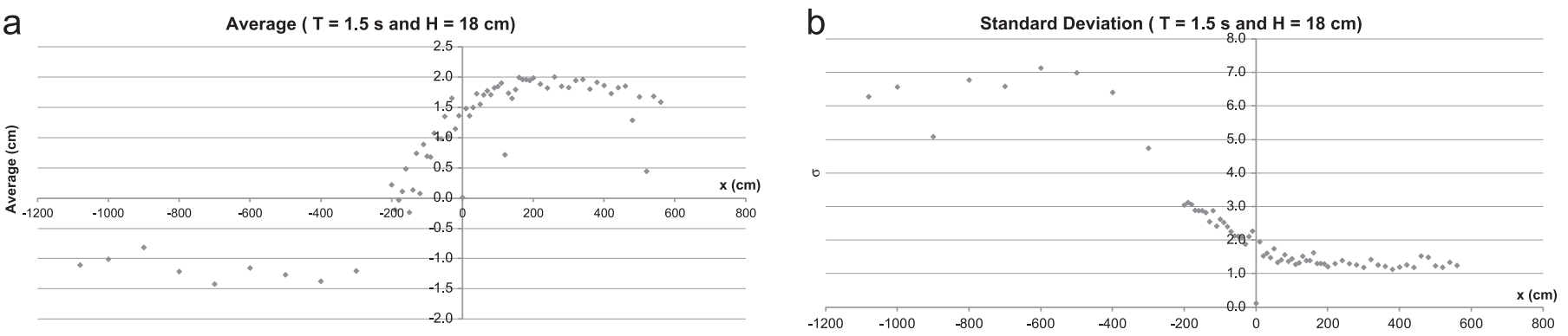

Fig. 8. (a) Average and (b) Standard deviation of the free surface elevation for an incident regular wave of $T=1.5 \mathrm{~s}$ and $H=18 \mathrm{~cm}$.

a

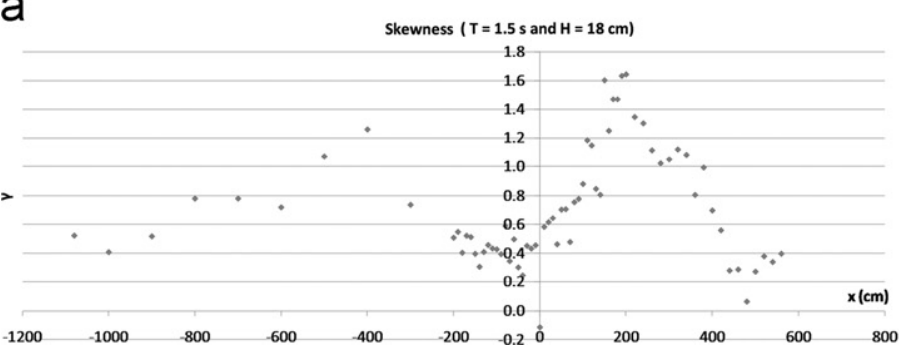

b

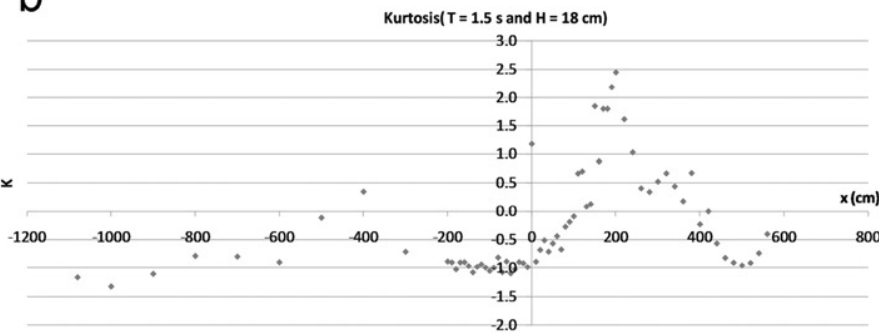

Fig. 9. (a) Skewness and (b) Kurtosis of the free surface elevation for an incident regular wave of $T=1.5 \mathrm{~s}$ and $H=18 \mathrm{~cm}$.

(see Table 2). After the breaking point the average free surface starts to increase until the end of the wave breaking section (see Table 2) (turbulence zone), and starts to stabilize around $x=200 \mathrm{~cm}$ till $x=400 \mathrm{~cm}$ where the average free surface begins to decrease.

The standard deviation (Fig. 8(b)) essentially reproduces the same as the wave significant heights (Fig. 8(a)): there is slightly increase related with the depth decreasing (shoaling effect) until $x=-500 \mathrm{~cm}$. During the wave breaking section, the standard deviation decreases significantly until $x=200 \mathrm{~cm}$ where the wave breaking starts to vanish. After that, the value of the standard deviation stills almost constant.

In Fig. 9, skewness and kurtosis values behave similarly. Initially, both present small values and begin to increase until the wave breaking point. After lowering considerably during the surf section, the skewness and the kurtosis rise significantly (approximately at $x=0 \mathrm{~cm}$ ) and falls again returning to values closer to the initial range (at $x=400 \mathrm{~cm}$ ), most probably due to the end of the generated turbulence of the wave breaking process.

The variations of the skewness are an indicator of the nonlinear effects due to the turbulent effects of the wave breaking phenomena.

Fig. 10 shows some of the calculated spectra for the incident wave condition of $T=1.5 \mathrm{~s}$ and $H=18 \mathrm{~cm}$, at the positions, $x=-1000 \mathrm{~cm}, x=-400 \mathrm{~cm}, x=0 \mathrm{~cm}$, and $x=400 \mathrm{~cm}$. The results for the spectral analysis show that as the wave propagates along the channel, there is an increasingly number of harmonics 
a
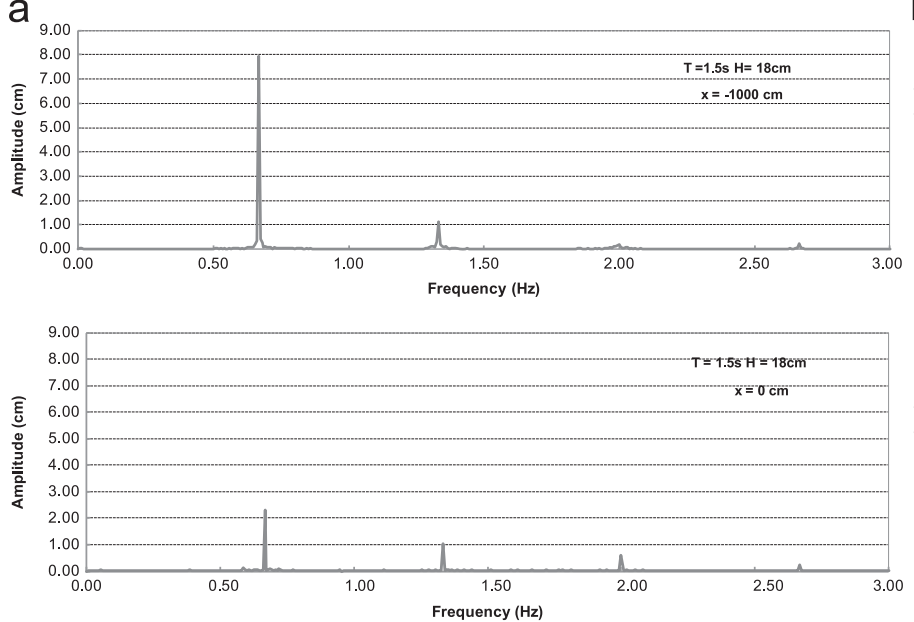

b
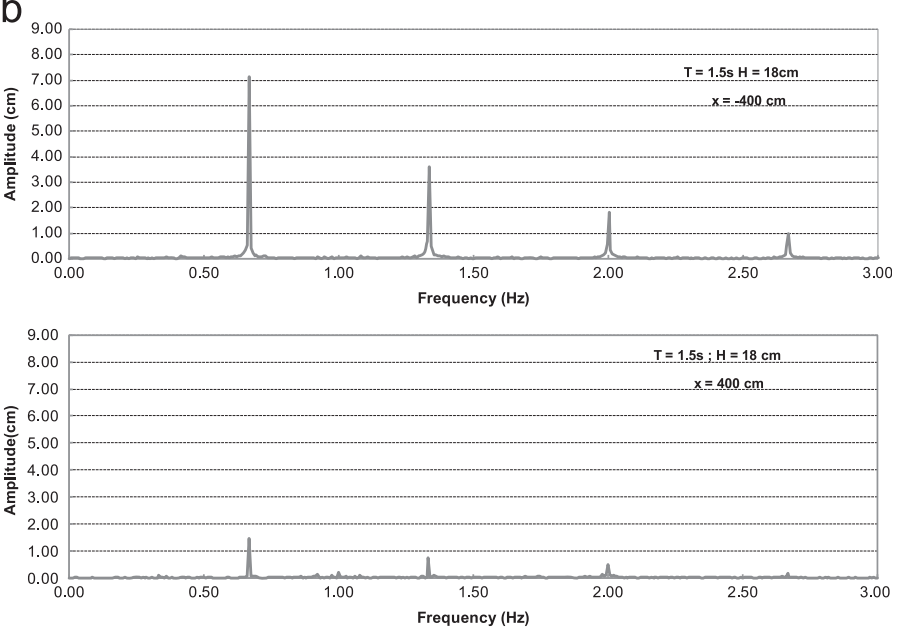

Fig. 10. Frequency spectra at the locations: $x=-1000 \mathrm{~cm}, x=-400 \mathrm{~cm}, x=0 \mathrm{~cm}, x=400 \mathrm{~cm}$; for the incident wave conditions of $T=1.5 \mathrm{~s}$ and $H=18 \mathrm{~cm}$.

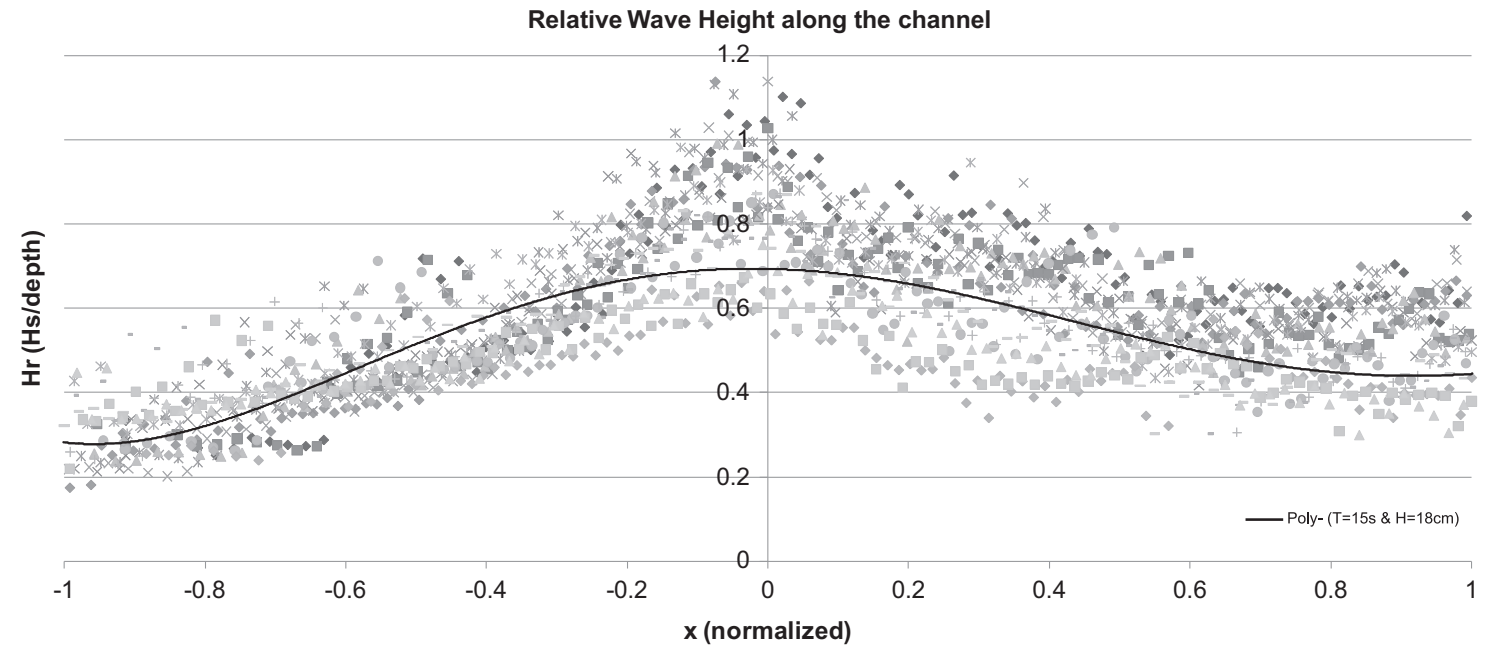

Fig. 11. Relative wave height evolution ( $X=0$ is the beginning and $X=1$ is the end of the wave breaking) along the bottom using a normalized scale for all the incident wave conditions. The "Poly. ( $T=1.5 \mathrm{~s} \& H=18 \mathrm{~cm}$ )" represents the trend line for the $T=1.5 \mathrm{~s}$ and $H=18 \mathrm{~cm}$ incident wave condition.

and a strong reduction in the amplitude of the main frequency. Comparatively, it is possible to observe that after the wave breaking, the amplitude of the main frequency decreases to the point of being almost similar to the other generated harmonics.

\subsubsection{Relative wave height}

The relative wave height $(H / d)$ (Fig. 11), is often used as an index for the wave breaking section in shallow water conditions. Dally et al. (1985) Considers this index as reference for a stabilized wave condition.

Unlike the beginning of the wave breaking, there is no standard or commonly used value for the end of the wave breaking section. Dally et al. (1985), indicates multiple values $(H / d=0.35-0.47)$ for different bottom slopes in order to get a curve that fits best the experimental results. Considering (Dally et al., 1985), it is expected that at the end of the surf section the relative wave height reveals values close to $H / d=0.35-0.47$, which is the value for an horizontal bottom case.

Fig. 11 shows, for all the 15 incident wave conditions, the relative wave height evolution from the top of the bar until the end of the surf section. In this case, the terminal location of the wave breaking section defined when the water bubbles disappear or the wave turbulence vanishes. The $x$-axis was normalized by the wave breaking section, so $x=0$ indicates the beginning of the wave breaking and $x=1$ indicates the terminal location of wave breaking (see 3.1).

From Fig. 11 it can be concluded that the behaviour of $H / d$ has two phases. Before the wave breaking zone the curve is steeper, increasing rapidly, while after the wave breaking, there is a decrease of $H / d$ and the slope presents a smoother curve. Moreover, in the wave breaking section, between $x=0.0$ and $0.6, H / d$ decreases until $H / d=0.40-0.65$ depending on the incident wave condition. After, this value remains almost constant until $x=1$. For an incident wave of $T=1.5 \mathrm{~s}$ and $H=18 \mathrm{~cm}$, the average rate of $H / d$ at the end of the wave breaking section, is of 0.45 .

An important conclusion of this figure, is that, while there is a great variation of $H / d$ at the beginning of the wave breaking $(H / d$ varies from 0.5 to 1.2 at $x=0.0 \mathrm{~cm}$ ) at the end of breaking, almost all values of $H / d$ are in the range of $0.35-0.65$.

\subsubsection{Wave celerity}

To calculate the wave celerity, it is necessary estimate the average time required for the passing waves between each two consecutive gauges using the free surface elevation data obtained with the eight gauges structure. The wave passing time was calculated as the one corresponding to the largest cross-correlation 
value between the full records of each pair of gauges. This method was applied by Okamoto et al. (2010). The full record of the wave gauges was used rather than sub-intervals of the same record.

Bellow, Fig. 12 shows the wave celerity results along the channel for the incident wave conditions of $H=18 \mathrm{~cm}$, and wave periods of $T=1.5 \mathrm{~s}, 2.0 \mathrm{~s}$ and $2.5 \mathrm{~s}$.

For the three wave periods, the celerity results demonstrate: (i) at the initial section, in the beginning of the 1:20 bar, there is an increase of the celerity; (ii) then, after $x=-400 \mathrm{~cm}$ where wave breaking occurs, the celerity decreases, following the depth reduction of the channel, starting first in the minor periods. This behaviour agrees with the occurrence of earlier wave breaking for shorter periods (see chapter 3.1); (iii) in the final section of the channel, the large reduction of the slope and the end of the wave breaking section motivates the curve smoothing and the tendency to collapse in one curve, independent from the different wave periods.

Fig. 13 is based on the results of the previous figure showing the ratio between the calculated celerity values and the theoretical celerity regarding the shallow water approximation $-\sqrt{g h}$.

In general, until $x=-200 \mathrm{~cm}$ there is an increase of the ratio between the measured celerity and the theoretical one, from 0.7 to 1.2. After that, the value of the ratio is almost constant until the end of the wave channel (between 1.1 and 1.2). As shown in the above Figs. 12 and 13 the $H(18 \mathrm{~cm}) T_{25}$ (s) values are slightly different from the other two, because of the breaking point of the $T=2.5 \mathrm{~s}$ wave that is around $50 \mathrm{~cm}$ different from the other two waves ( $1.5 \mathrm{~s}$ and $2.0 \mathrm{~s}$ ) (see Table 2 ).

\subsection{Phase II results}

In this section, examples of particle velocity data and data analysis are presented. For each incident wave condition, the data analysis, along the longitudinal $(x)$ axis of the channel, consists on the:

I. Time and statistical analysis of the particle velocity time series along the $x$ axis $\left(V_{x}\right)$;

II. Characterization of the shape of the two-dimensional distributions of the velocity components in the three orthogonal planes;

III. Evaluation of the mean wave direction and the directional spread along the longitudinal axis of the channel.

3.3.1. Time, spectral, and statistical analysis of the velocity data

The average of the velocity values at each record was calculated through the average of all measured values in the record. The averages of the maximum and minimum velocities were calculated by the identification of each "wave" using the criterion of the downward zero crossing. Each intersection was considered effective when there were at least two points before and after the zero reference.

The statistical analysis consisted in determining the standard deviation, variance, skewness and kurtosis of the particle velocity values $\left(V_{x}\right)$, recorded at a point for each incident wave condition along the $x$-axis position (longitudinal direction and positive values toward the wave maker).

Below, the figures (Figs. 14-16) present the data and results for an incident wave of $T=1.5 \mathrm{~s}$ and $H=18 \mathrm{~cm}$, namely: (i) time series of $V_{x}(x=-900 \mathrm{~cm})$; (ii) variation of the average velocity values $\left(V_{x}\right)$; (iii) standard deviation, skewness, and kurtosis of the recorded $V_{x}$ values along the $x$ axis (from the position $x=-1000 \mathrm{~cm}$ to position $x=560 \mathrm{~cm})$.

As observed in Fig. 14(a), after the breaking point (near $x=-400 \mathrm{~cm}$ ), the average values of the $V_{x}$ velocities increase abruptly and when the wave collapses (around $x=-200 \mathrm{~cm}$ )

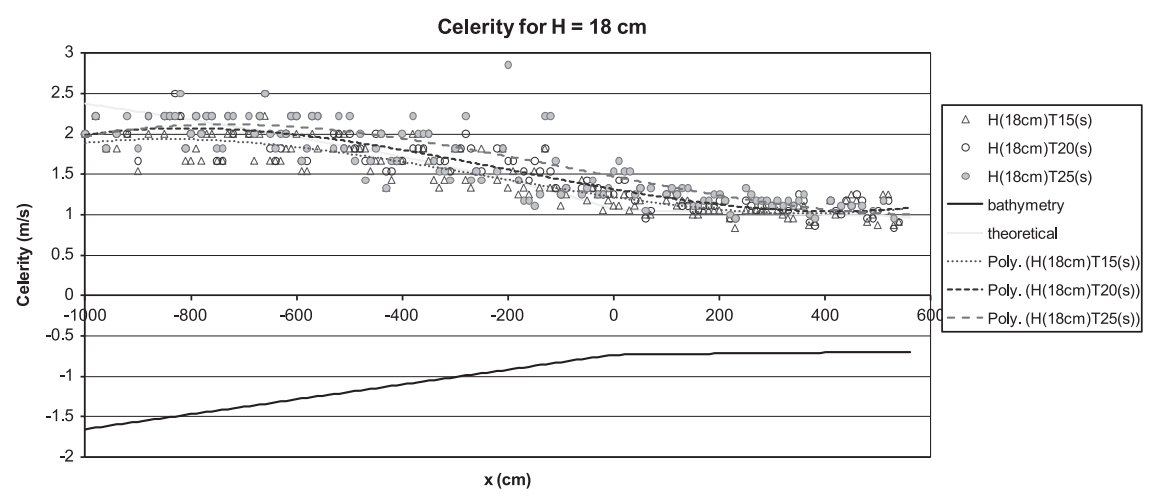

Fig. 12. Wave celerity results along the channel for incident waves of $H=18 \mathrm{~cm}$ and $T=1.5 \mathrm{~s}, 2.0 \mathrm{~s}$ and $2.5 \mathrm{~s}$. In the legend, the fit curves "Poly. ( $H(18 \mathrm{~cm}) T 15$ (s))", "Poly $(H(18 \mathrm{~cm}) T 20(\mathrm{~s}))$ " and "Poly $(H(18 \mathrm{~cm}) T 25(\mathrm{~s}))$ " correspond to the " $H(18 \mathrm{~cm}) T 15(\mathrm{~s})$ ", " $H(18 \mathrm{~cm}) T 20(\mathrm{~s})$ "and " $H(18 \mathrm{~cm}) T 25(\mathrm{~s})$ " waves.

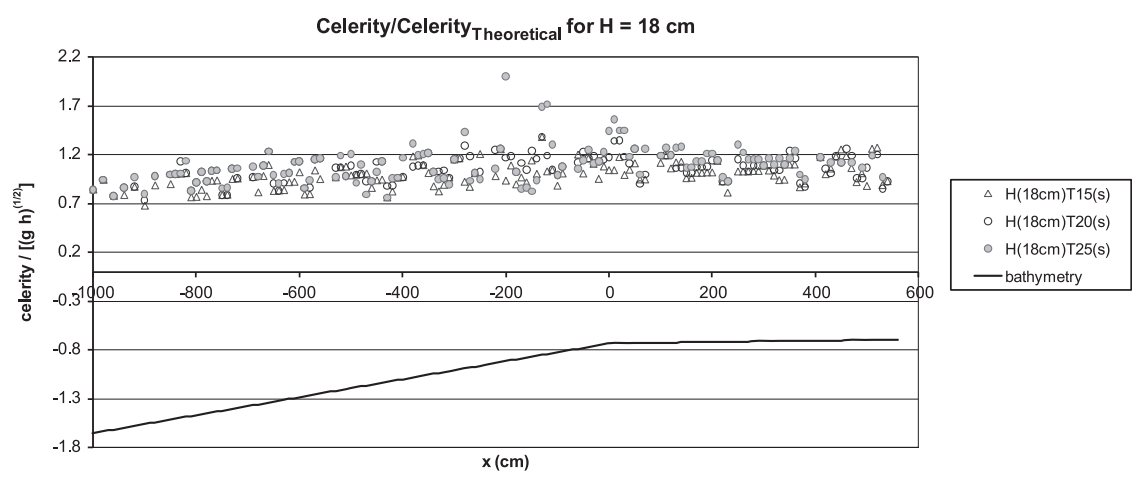

Fig. 13. Ratio between the calculated values of the celerity and the theoretical celerity for the wave periods of $1.5 \mathrm{~s}, 2.0 \mathrm{~s}$ and $2.5 \mathrm{~s}$. 


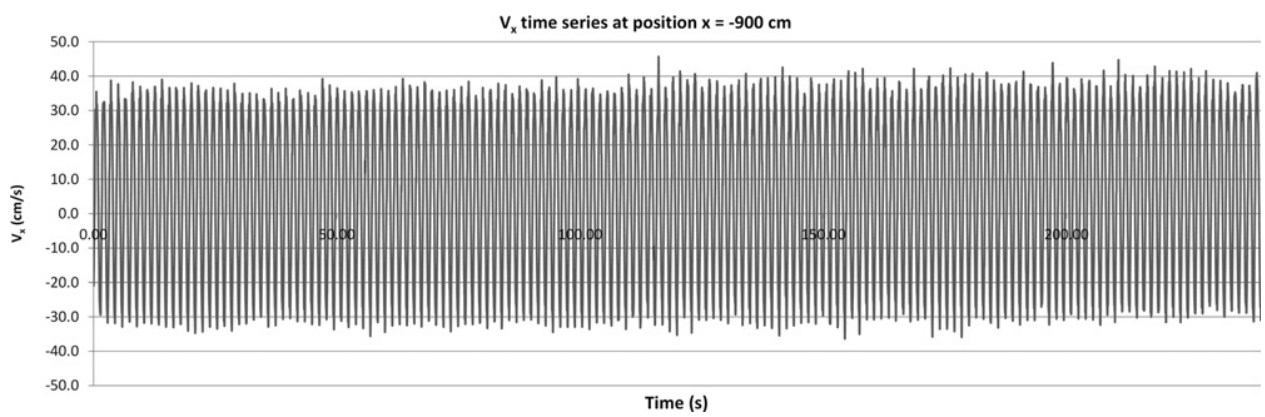

Fig. 14. Velocity $\left(V_{x}\right)$ at the position $x=-900 \mathrm{~cm}$, for an incident wave of $T=1.5 \mathrm{~s}$ and $H=18 \mathrm{~cm}$ (The positive $V_{x}$ values are referred towards the paddle).

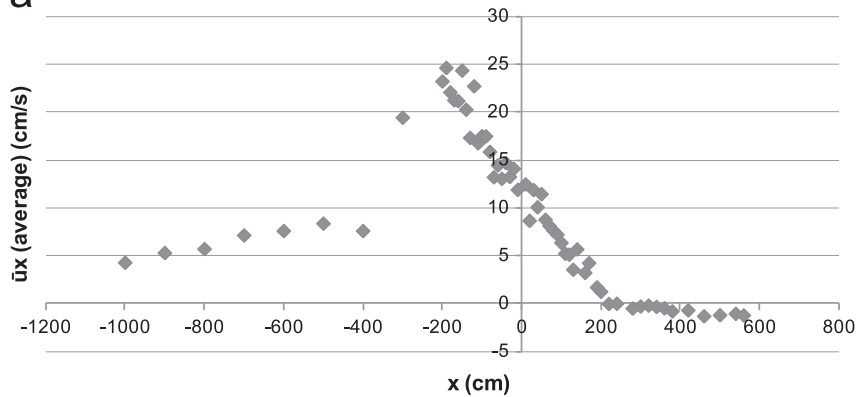

b

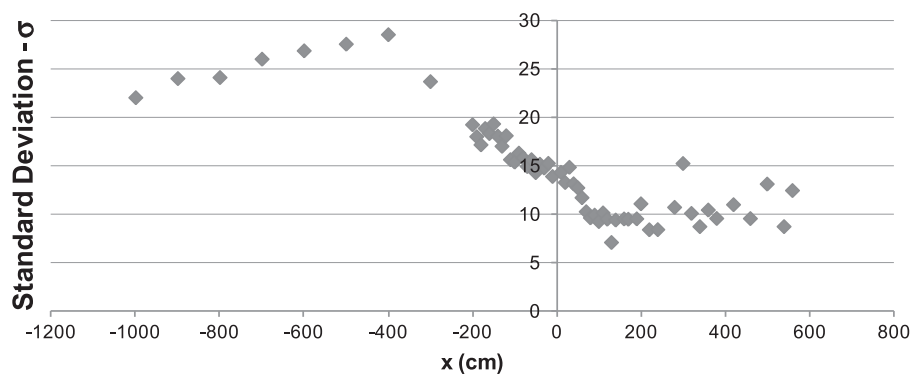

Fig. 15. (a) Average and (b) the standard deviation of the velocity $\left(V_{x}\right)$ values along the channel, for an incident wave of $T=1.5 \mathrm{~s}$ and $H=18 \mathrm{~cm}$ (positive $V_{x}$ values are referred towards the paddle).

a

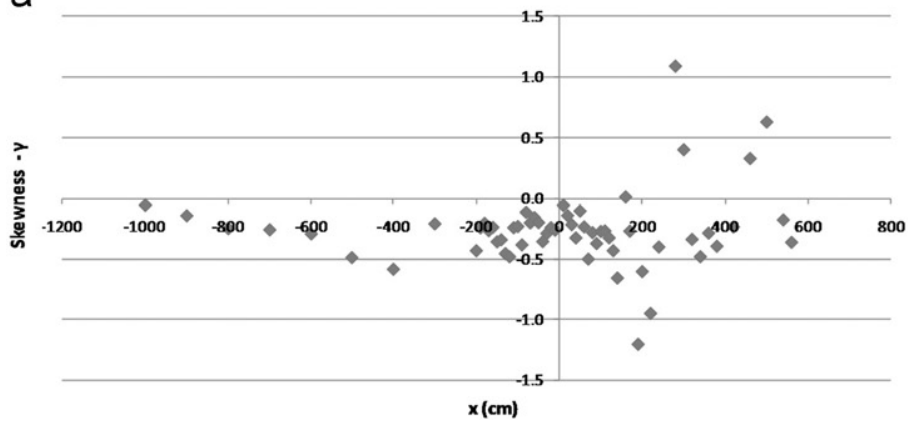

b

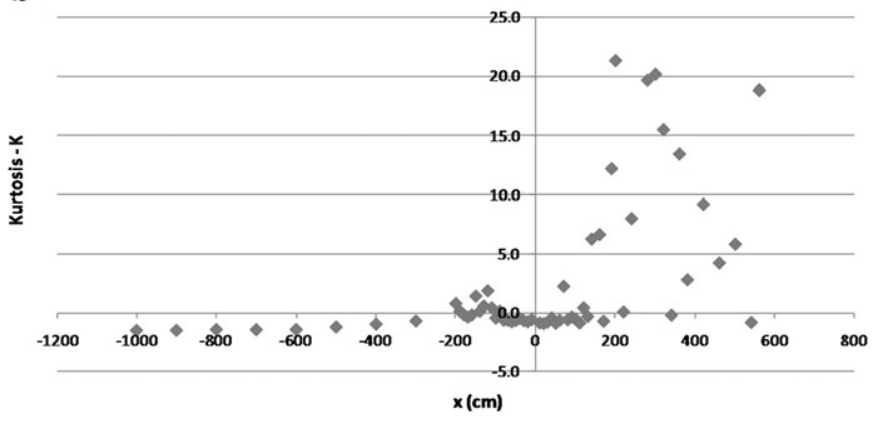

Fig. 16. (a) Skewness and (b) Kurtosis of the velocity $\left(V_{x}\right)$ values along the channel, for an incident wave of $T=1.5 \mathrm{~s}$ and $H=18 \mathrm{~cm}$.

those values start to decrease till become almost constant by the end of the wave breaking, after $x=200 \mathrm{~cm}$. Also, the Fig. 15(a) shows that there is a small return flow before the initiation of the wave breaking, however this small flow proves to be very small comparing with the wave breaking section, the stokes drift can explain the values presented, they reflect the typical onshore flow in such conditions. After the wave breaking due to the low steepness of the ramp the values are proved to be very close to zero and even show a tendency for a flow towards the end of the channel (negative $V_{x}$ values).

The standard deviation, Fig. 15(b), depicts values that are similar to the average of the velocities: first an increment till the wave breaking point, followed by a decrease till $x=50 \mathrm{~cm}$. After that, the values of the standard deviation are almost constant, some oscillation occurs probably due to the harmonics generation, because of the bottom slope or by the wave breaking effect.

For the skewness and the kurtosis (Fig. 16), a general trend can be observed indicating huge differences at the end of the wave breaking (after $x=100 \mathrm{~cm}$ ) possibly due to the above mentioned appearance of some waves generated by the bottom slope and by the wave breaking effect.

\subsubsection{Two-dimensional distribution of the three orthogonal} components of the velocity

In this section, the analysis of the two-dimensional distributions of the velocity components in the $x y, x z$ and $y z$ planes is performed. First, the procedure followed the evaluation of the parameters $E_{x}, E_{y}, E_{z}$ (Fig. 17). $E_{x}, E_{y}$ and $E_{z}$ are the difference between the averages of the positive and negative velocities for each orthogonal component $(x, y, z)$ measured by the ADV.

In Fig. 18 , the $E_{z} / E_{x}, E_{y} / E_{x}$ and $E_{y} / E_{z}$ ratios are represented for an incident wave condition of $T=1.5 \mathrm{~s}$ and $H=18 \mathrm{~cm}$.

Table 3 supports the values from the above figures allowing a faster interpretation of the results:

From Fig. 18, one can conclude that at the beginning of the channel and approaching the wave breaking zone, the distributions ratios present $E_{y} / E_{x}<0.1$ and $E_{y} / E_{z}<0.4$, not far from the ideal, $E_{y} / E_{x}=E_{y} / E_{z}=0$.

Later, with an increase in the ratios values involving the parameter $E_{y}$, the results remain fairly unchanged until the position near $x=-500 \mathrm{~cm}$, when a new change is felt, particularly considering the ratio $E_{y} / E_{z}$. 
If there was no wave breaking, $\left(E_{z} / E_{x}\right)$ (Fig. 18(a)) would show a continuous decrease as the wave propagates towards the shallower region because of the orbit shape. However with the wave breaking phenomena, the values depict the decrease trend of $E_{z} / E_{x}$. Therefore, the bump-up during the wave breaking in $x-z$ plane displays the turbulence effect on the velocity measurements.

The position $x \cong-400 \mathrm{~cm}$ represents the beginning of the wave breaking section, from this point an abrupt increase of the $E_{z} / E_{x}$ ratio occurs till $x=-200 \mathrm{~cm}$. For $x>-200 \mathrm{~cm}$, the values decrease, forcing a stretch of the waveform in the longitudinal direction of the channel.

Interesting is to observe that the wave breaking affects differently the three ratios $\left(E_{z} / E_{x} ; E_{y} / E_{x} ; E_{y} / E_{z}\right)$. Following $E_{z} / E_{x}$ the response to the wave breaking is felt $100 \mathrm{~cm}$ later than both $E_{y} / E_{x}$ and $E_{y} / E_{z}$. Around $x=-400 \mathrm{~cm}$ the $E_{z} / E_{x}$ starts to increase, meanwhile the curves of the ratios $E_{y} / E_{x}$ and $E_{y} / E_{z}$ had already begun to increase around $x=-500 \mathrm{~cm}$.
Fig. 18 shows clearly the transformation of the $E_{x}$ component into the $E_{z}$ and $E_{y}$ components. The transverse velocity $\left(E_{y}\right)$ starts to show some fluctuation slightly before the wave breaking initiation, this might indicate the influence of the wall due to the narrow width of tank. After, during the wave breaking process the rolling effect of the wave that obliges the water spreading, this way, the transverse component $\left(E_{y}\right)$ is probably due to the turbulent mixture from the roller effect of the breaking wave, which starts around $x=-500 \mathrm{~cm}$.

An important observation can be taken from the Fig. 18, the values show that the amplitude of $V_{x}$ roughly follows the wave height change, i.e., Fig. 18(b), this shows the small turbulence intensity considering the wave motion. This proves the existence of turbulence. Comparing to the $V_{x}$ values, the $V_{z}$ has smaller amplitude because of the shallow water depth at the wave breaking section, as consequence it leads to an increase of the turbulence effect on the wave motion. a

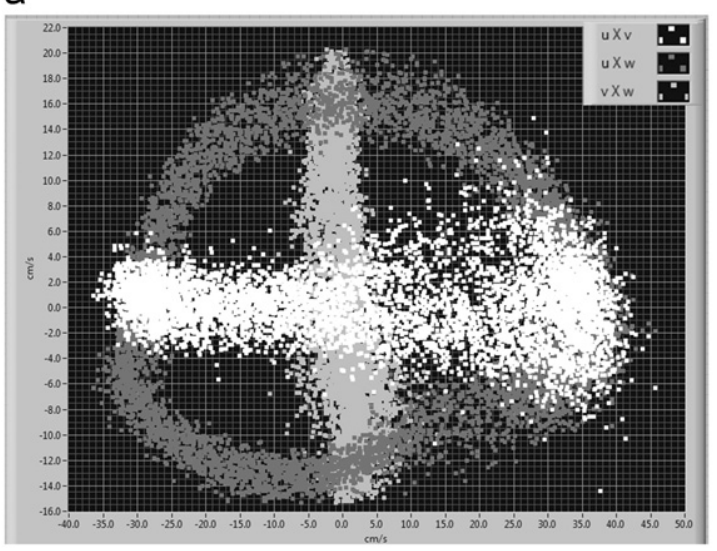

b

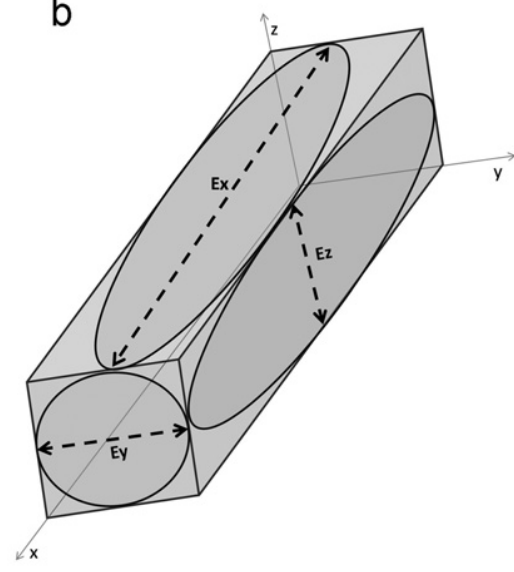

Fig. 17. Typical two-dimensional distributions of the velocity components (a) the recorded data cloud and (b) parameters lengths schematically represented.

a

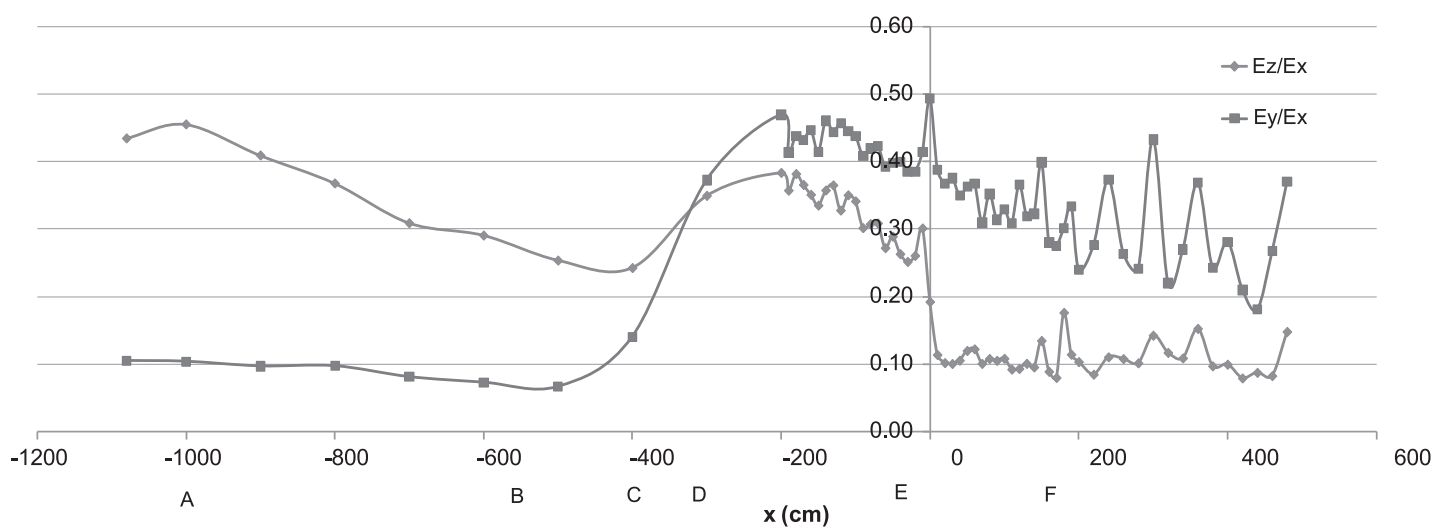

b
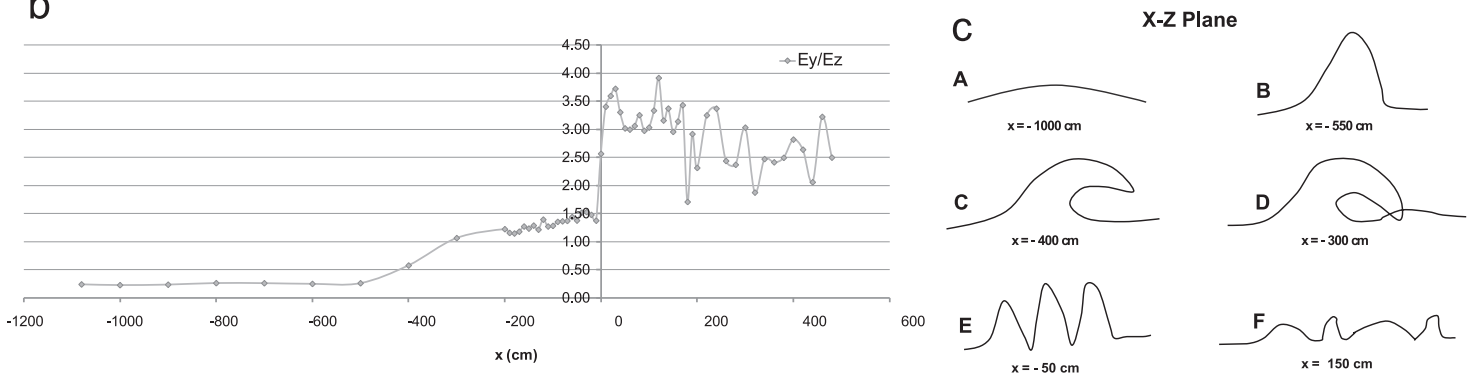

Fig. 18. (a) $E_{z} / E_{x}$ and $E_{y} / E_{x}$; (b) $E_{y} / E_{z}$ ratios along the $x$ axis of the channel, for an incident wave of $T=1.5 \mathrm{~s}, H=18 \mathrm{~cm}$ and (c) wave shape in the $x z$ plane in various positions along the channel (A to $\mathrm{F}$ ). 


\subsubsection{Mean wave direction and directional spread}

The main highlight of this work is the directional spreading model for the definition of the wave breaking sections (based on the simultaneous measurements of the particle velocities and the free surface values). At first, this approach would not make sense in a 2D wave channel. Nevertheless, due to the generated turbulence in the wave breaking process, the directional spread is observed along the wave propagation on the wave channel. Thus, the directional analysis of the experimental data may constitute a framework for the turbulence quantification associated with the wave breaking phenomena.

According to Trageser and Elwany (1990), several measurement techniques and analysis can be used to obtain the directional spectra. For each application, the desired degree of directional description can range from a complete set of wave characteristics to a very condensed description in terms of few parameters, such as, for example, the predominant wave direction. For many applications involving the wave directionality, the mean wave direction $\theta(f)$ and directional spread $s(f)$, depending on the frequency, provide enough information.

To obtain the directional wave spectrum the method developed by Longuet-Higgins (Dean and Dalrymple, 1993) can be used. This method, in addition to the free surface elevation records, considers also the simultaneous records of the velocities in the horizontal plane distribution. In this method, the directional spectrum is expressed by the Fourier series.

As shown by Trageser and Elwany (1990), the Fourier series, which represent the spreading function $D(\theta)$, can be written by:

$D(\theta)=\frac{1}{2} \pi+\sum_{n}\left[A_{n} \cos (n \theta)+B_{n} \sin (n \theta)\right] / \pi$

working, for example, with the free surface elevations $(\eta)$ and current velocities $(u, v)$, the four Fourier coefficients can be estimated, $A_{1}, B_{1}, A_{2}$ and $B_{2}$, through the expressions:

$A_{1}=\frac{C_{\eta v}}{\left[C_{\eta \eta}\left(C_{u u}+C_{v v}\right)\right]^{1 / 2}}$

Table 3

Results interpretation for the $E_{z} / E_{x}, E_{y} / E_{x}$ and $E_{y} / E_{z}$ ratios.

\begin{tabular}{llll}
\hline Ratio & Results & $\begin{array}{l}\text { Graphical appearance } \\
\text { of the points cloud }\end{array}$ & Channel view \\
\hline $\boldsymbol{E}_{\boldsymbol{z}} / \boldsymbol{E}_{\boldsymbol{x}}$ & $>1$ & $\begin{array}{l}\text { Elongated vertically } \\
\text { Circular }\end{array}$ & Side \\
& $=1$ & $\begin{array}{l}\text { Elongated longitudinally } \\
\text { Line (ideal condition) }\end{array}$ & Front \\
$\boldsymbol{E}_{\boldsymbol{y}} / \boldsymbol{E}_{\boldsymbol{x}}$ & $=0$ & Transverse components $\neq 0$ & \\
& $>0$ & Line (ideal condition) & Top \\
$\boldsymbol{E}_{\boldsymbol{y}} / \boldsymbol{E}_{\boldsymbol{z}}$ & $=0$ & Transverse components $\neq 0$ & \\
& $>0$ & & \\
\hline
\end{tabular}

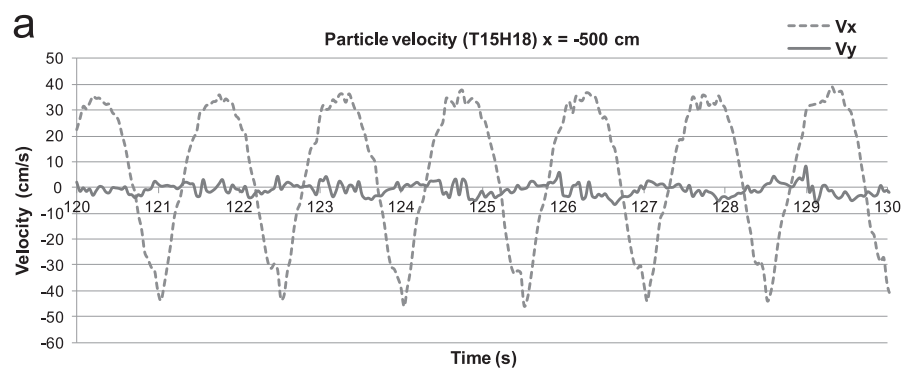

$$
B_{2}=\frac{C_{v u}}{C_{v v}-C_{u u}}
$$

where $C$ represents the real part of the spectrum (co-spectrum), $\eta$ is the elevation, $u$ is the north velocity (longitudinal axis of the channel) and $v$ is the velocity in the transverse direction of the channel. The mean wave direction $\theta(f)$ and directional spread $s(f)$ can be calculated using

$\theta(f)=\arctan \left(\frac{A_{1}}{B_{1}}\right)$

and

$s(f)=[2(1-r)]^{1 / 2}, \quad r^{2}=A_{1}{ }^{2}+B_{1}{ }^{2}$

According to Trageser and Elwany (1990), the estimation of the mean wave direction as a function of frequency $\theta(f)$ is accurate. However, the estimation of the directional spread value can be coarse for a limited number of coefficients.

The mean wave direction and the directional spread are calculated using the simultaneous measurements of the particle velocity and the free surface elevation made at the same transverse section along the $x$ axis of the channel.

To identify regions with potential quality reduction of the directional analysis it is required to check the records minutely. As an example, from Fig. 19, parts of the measurements corresponding to an incident wave height of $18 \mathrm{~cm}$ and period of $1.5 \mathrm{~s}$. The presented measurements refer to the longitudinal position (a) $x=-500 \mathrm{~cm}$ and (b) $x=100 \mathrm{~cm}$ of the wave channel. In the figure, $V_{x}$ and $V_{y}$ are the velocity components towards the longitudinal and transverse directions, respectively. The positive $V_{x}$ velocity values are referred towards the paddle of the wave maker.

As the ADV approaches the wave breaking region, at $x=-400 \mathrm{~cm}$ an amplitude growth for the velocity records in the transverse direction of the channel $\left(V_{y}\right)$ occurs.

Although, according to Table 4 below, the mean wave direction remain around the original generation value $\left(270^{\circ}\right)$, the growth of the directional spread during the wave breaking process is remarkable.

The obtained results for the directional spread and mean wave direction are shown through the Fig. 20 below. The wave propagation from the generation paddle presents an angle of $270^{\circ}$, in a parallel direction to the longitudinal axis of the channel. It is visible the directional spread oscillation during the wave breaking zone.

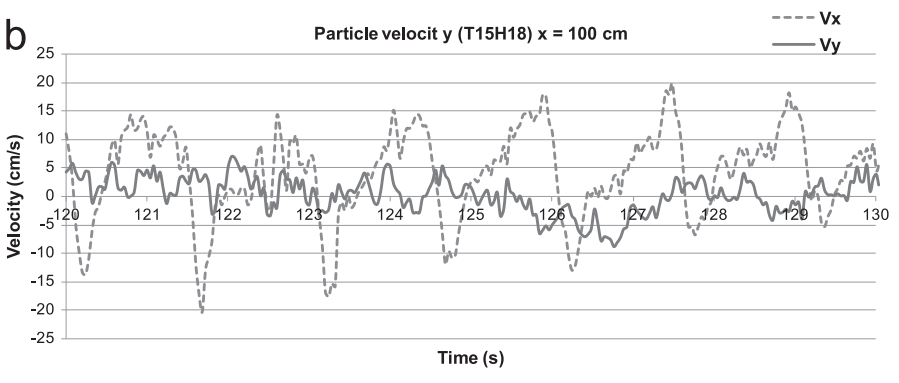
the paddle). 
Usually the directional spread is used only when multiple components propagate in various directions. As we can observe from Fig. 20 the breaking wave still propagates at the same direction and keeps the wave train unchanged. However, from the significant variation of the spreading angle from $x=-395 \mathrm{~cm}$ to $x=200 \mathrm{~cm}$, we can observe clearly the wave breaking section. In fact, this analysis presents very low spreading values before the wave breaking, increasing during the wave breaking, specially just before $x=0$, in order to decrease considerably after in the end of the wave breaking section. As shown, the spreading angle values are largely due to the generated turbulence of the wave breaking effect and to the bottom slope variation. In general, from the obtained data, the wave breaking section is defined mainly by spreading angles above the value of 7 . Obviously further experiments are necessary to confirm an exact number for the spreading angle to define the wave breaking section.

However, the spreading values after the wave breaking are slightly greater than the ones before the wave breaking. This might also indicate that after the wave breaking, the residual frequency changes into more waves with different frequencies that propagate independently. This change in the main component of the generated wave in the channel is discussed more deeply at Okamoto et al. (2010). This can be confirmed at Fig. 10, where one can see the generation of wave components that differ from the wave main frequency after the wave breaking.

Table 4

Mean wave direction and directional spread of an incident wave of $T=1.5 \mathrm{~s}$ and $H=18 \mathrm{~cm}$.

\begin{tabular}{ccc}
\hline Channel oosition (cm) & Mean wave direction (deg.) & Directional spread (deg.) \\
\hline-1080 & 269.5 & 4.0 \\
-500 & 271.5 & 1.9 \\
-300 & 270.9 & 9.9 \\
-100 & 272.0 & 13.9 \\
60 & 271.1 & 11.3 \\
100 & 272.6 & 9.9 \\
170 & 272.7 & 6.0 \\
240 & 272.6 & 10.4 \\
340 & 275.2 & 7.1 \\
460 & 273.0 & 4.6 \\
500 & 271.1 & 6.3 \\
540 & 269.3 & 6.7 \\
\hline
\end{tabular}

\section{Conclusions}

In this paper, recent physical modelling tests on a wave channel from the National Laboratory of Civil Engineering in Lisbon (LNEC), Lisbon, Portugal, were presented. The tests aimed mainly to introduce a new analysis based on the directional spread of the wave on a wave channel to study the wave breaking hydrodynamics on complex bathymetries, namely bathymetries with variable bottom slopes. This work represented a step forward to understand and better define the wave breaking process throughout the surf section since the beginning till the very end, considering incident wave conditions.

The physical modelling was performed on a wave channel, built for wave propagation studies, with a bottom characterized by two ramps with $1: 20$ and 1:80 slopes, respectively, forming a characteristic beach profile. The tested waves resulted from a combination of $1.1 \mathrm{~s}, 1.5 \mathrm{~s}, 2.0 \mathrm{~s}$ and $2.5 \mathrm{~s}$ periods with wave heights of $12 \mathrm{~cm}, 14 \mathrm{~cm}, 16 \mathrm{~cm}$ and $18 \mathrm{~cm}$. The initial and final location of the wave breaking section was observed. The measured data from the resistive gauges (free surface elevation) and the Acoustic Doppler Velocimeter (ADV) enabled a time, spectral and statistical analysis and the calculation of several parameters, such as the wave celerity, the relative wave heights, the twodimensional distributions of the velocity components in the $x y, x z$ and $y z$ planes, culminating in the calculation of the mean wave direction and the directional spread of the wave propagation.

From the physical model (wave channel), a wide set of wave data (free surface elevation and particle velocity) along the channel and especially in the wave breaking section is available. These data and the results obtained from the performed analysis constitute important outputs since they can be used to understand deeply the wave breaking process, but also for the establishment/improvement of the wave breaking numerical models and its validation.

Considering the relative wave height results, the behaviour of $H / d$ has two distinct phases: before the wave breaking there is an increase of the $H / d$ (due to shoaling effect) and the slope curve is steeper, while after, there is a decrease of the $H / d$ and the slope presents a smoother curve. Moreover, in the breaking zone, one can also observe that in the first $60 \%$ of the surf section, the $H / d$ decreases until $H / d=0.40-0.65$ depending on the incident wave condition. These values are relatively high comparing with the (Dally et al., 1985) tests for a horizontal bottom. However, the results do not differ much from the expected. After this, in the

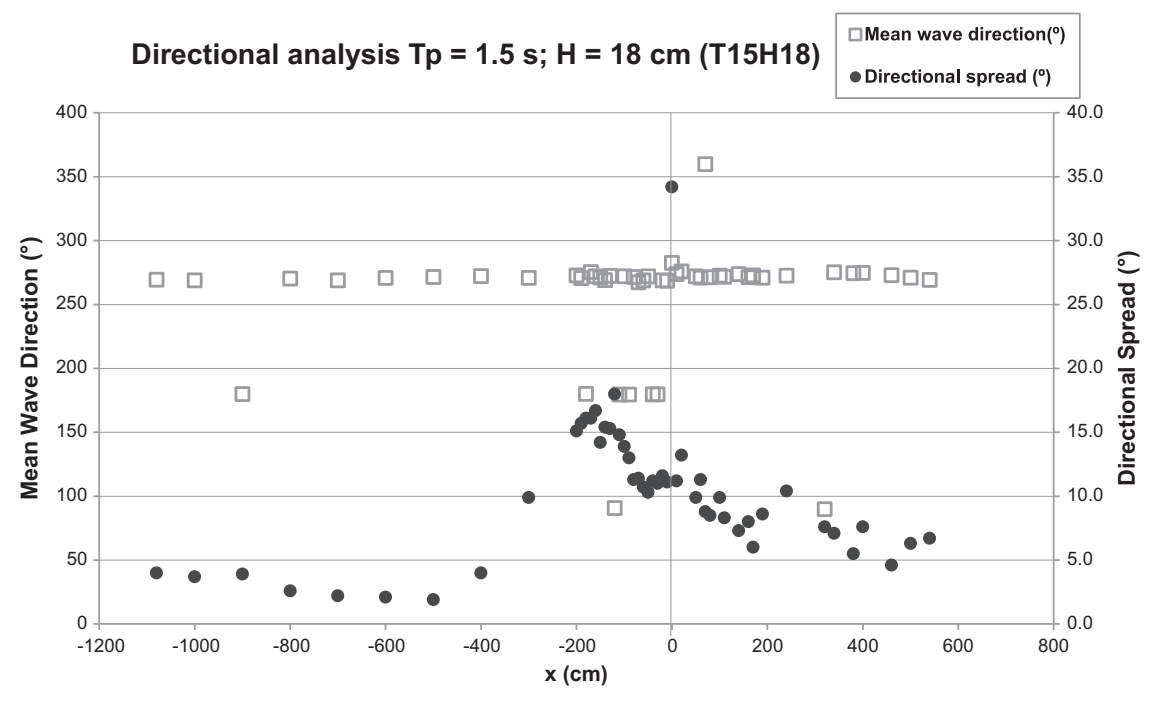

Fig. 20. Mean wave direction $\left({ }^{\circ}\right)$ and directional spread $\left({ }^{\circ}\right)$ for an incident wave of $T=1.5 \mathrm{~s}$ and $H=18 \mathrm{~cm}$. 
later $40 \%$ of the surf section, these values remain almost constant until $x=1$.

The directional analysis showed that the directional spread presents very low values before the wave breaking, increasing clearly right after and during the wave breaking, in particular right before the crest of the 1:20 slope ramp, in order to decrease considerably at the end of the wave breaking zone. This work shows, briefly, that the directional spread is directly connected with the turbulent effects due to the wave breaking phenomena. Thus, the calculation of the directional spread from the directional analysis, may serve as an index for the turbulence generated by the wave breaking on a 2D physical model, such as the wave channel presented in this paper.

Along the channel, as the wave begins to break, the observed parameters related to the velocity components, $E_{x}, E_{z}$ and mainly $E_{y}$, begin to increase, mostly on the transverse component of the wave direction at the horizontal plane $\left(E_{y} / E_{x}\right)$. Such an increasing is related with major values of turbulence intensity and Reynolds stresses that are responsible for the intensification of the mixing processes. Simultaneously this mixing phenomenon is felt on the directional spreading calculation, since the used method applies cross-spectral calculations between the velocity components $u$ and $v$. Such calculation shows a direct liaison between the values of all the referred parameters.

The work here presented shows that the directional spreading model proved to be sensitive to the turbulence generated by the wave breaking process. This explains the greater values of the directional spread during and after the surf zone, however, the performed analysis allows the definition of a value of the directional spread that limits the breaking wave section.

The relative wave height index is often used to define a wave breaking section on wave channels, this way we can compare the directional spreading model with the relative wave height index.

One should note that the results are quite sensible according to the quality of the free surface and the velocity measurements. Thus, any problems in positioning the resistive gauges and the occurrence of air bubbles in the water, appear as important parcels, stacked to the results. These problems mostly occurred in the wave breaking region, where the resistive wave gauges, were eventually, briefly out of the water and the ADV measured velocities with high occurrence of air bubbles which possibly invalidate its use. However, the results show that the measured data present enough quality to draw relevant conclusions for the proposed study.

This study presents a different approach on the definition of parameters that enable the definition of a wave breaking section on a wave channel. Hereby the directional spreading model allowed the characterization of the turbulent zone generated through the breaking of the wave on the wave channel. This method can be applied on numerical models and for an extensive analysis of the breaking wave process on in physical 2D models.

Future work concerns a more complete analysis of the directional spreading model here presented, and the comparison with other parameters for the wave breaking definition. A further analysis on the wave breaking physical process is also needed.

In order to be useful for the scientific community, the experimental data here presented is available online by <http:// www-ext.lnec.pt/projects2012/BRISA_COI3/ > .

\section{Acknowledgments}

The authors gratefully acknowledge the financial support of Fundação para a Ciência e a Tecnologia, Portugal, through the project PTDC/ECM/67411/2006 and through the project "Construindo uma base para pesquisa e conhecimento em Engenharia Costeira" financed by CAPES/ FCT (cooperation Portugal/Brazil).

\section{References}

Camenen, B., Larson, M., 2007. Predictive formulas for breaker depth index and breaker type. J. Coastal Res. 23 (4), 1028-1041.

Dally, W.R., Dean, R.G., Dalrymple, R.A., 1985. Wave height variation across beaches of arbitrary profile. J. Geophys. Res. 90 (C6), 11,917-11,927.

Dean, R.G., Dalrymple, R.A., 1993. Water Wave Mechanics for Engineers and Scientists. World Scientific, Singapore.

Dean, R.G., Walton, T.L., 2009. Handbook of Coastal and Ocean Engineering. World Scientific, Chapter 1 .

Fortes, C.J., Ferreira, Ó., Silva, P., Sancho, F., Neves, D.R.C.B., Rocha, M.; Moura, T., Pinheiro, L., Capitão, R., Didier, E. , Neves, M.G., Bezerra, M.M., Abreu, T., 2011. Rebentação das ondas e o transporte de sedimentos. O Projecto BRISA. Wave Breaking and the Sediment Transport. Project BRISA (in Portuguese). $7^{\text {as }}$ Jornadas Portuguesas de engenharia costeira e portuária (JPECP), FEUP, Porto.

Goda, Y., 1970. A synthesis of breaking indices. Trans. JSCE 2 (2), 39-49.

Lesieur, M., 1997. Turbulence in Fluids. Kluwer Academic Publishers, London.

Okamoto, T., Fortes, C.J., Basco, D.R., 2008. Wave breaking termination on bartrough shaped beaches. In: Proceedings of the 18th International Offshore and Polar Engineering Conference, pp. 811-819.

Okamoto, T., Fortes, C.J., Basco, D.R., 2010. Bore propagation speed at the termination of wave breaking. Coastal Eng.

Sancho, F., Mendes, P.A., Carmo, J.A., Neves, M.G., Tomasicchio, G.R., Archetti, R. Damiani, L., Mossa, M., Rinaldi, A., Gironella, X., Arcilla, A.S., 2001. Wave hydrodynamics over a barred beach. Proceedings of International Symposium on Ocean Wave Measurement and Analysis. "Waves 2001". S. Francisco, ASCE.

Svendsen, I.A. Madsen, P.A., Hansen, J.B. 1978. Wave characteristics in the surf zone. Proceedings of 16th ICCE. ASCE, 520-539.

Trageser, J.H., Elwany, H., 1990. The S4DW, an integrated solution to directional wave measurements. Proceedings of IEEE Working Conference on Current Measurement, pp. 1-14.

Tsai, C.P., Chenb, H.B., Hwungc, H.H., Huang, M.J., 2004. Examination of empirical formulas for wave shoaling and breaking on steep slopes. Ocean Eng. 32 (3-4), 469-483.

Weggel, J.R., 1972. Maximum breaker height. J. Waterway. Div.-ASCE 98, 529-554. 